\title{
A prospective study of intrauterine death cases at a tertiary care hospital
}

\author{
Nabila N. Tai*, Rinku Mulchandani, Dipti A. Modi, Bijal Rami
}

Department of Obstetrics and Gynaecology, Medical College Baroda, Baroda, Gujarat, India

Received: 07 December 2020

Accepted: 12 January 2021

*Correspondence:

Dr. Nabila N. Tai,

E-mail: nabilatai93@gmail.com

Copyright: () the author(s), publisher and licensee Medip Academy. This is an open-access article distributed under the terms of the Creative Commons Attribution Non-Commercial License, which permits unrestricted non-commercial use, distribution, and reproduction in any medium, provided the original work is properly cited.

\section{ABSTRACT}

Background: Intrauterine fetal death is defined as foetus with no signs of life in utero after 20 weeks of gestations. Stillbirth is a useful index to measure the values of antenatal and intra-natal care. Intrauterine fetal death is due to various causes whether it be maternal causes, fetal causes or placental causes.

Methods: It was a prospective study, conducted at SSG hospital, Vadodara over a period of 1 year from January 2019 to December 2019. All pregnant women coming to labour room with intrauterine fetal death with gestation age more than 28 weeks were included in study. It included complaints on admission, obstetric profile, mode of delivery, fetal outcomes, placental examination, condition of cord and investigation reports.

Results: During the study period of one year, a total of 462 intrauterine fetal deaths were reported amongst 7295 deliveries conducted during the study period. Incidence rate calculated was 63/1000 births. Many of the intrauterine fetal death cases were associated with pregnancy induced hypertension and antepartum hemorrhage. Out of all intrauterine death cases, 410 cases delivered vaginally. Congenital anomalies were also found to be associated with intrauterine death cases.

Conclusions: High risk pregnancy cases should be identified during routine antenatal check-ups so that intrauterine fetal death can be prevented. The mode of antepartum and intrapartum surveillance for fetal wellbeing should be advanced to prevent fetal demise.

Keywords: Antepartum hemorrhage, Congenital anomalies, Intrauterine death, Pregnancy induced hypertension, Still birth

\section{INTRODUCTION}

Fetal death means death prior to complete expulsion or extraction from mother of product of conception irrespective of period of gestation and which is not induced termination. ${ }^{1}$ The death is indicated by the fact that fetus does not breath or show any other evidence of life. ${ }^{1}$

As per the WHO Definition, an Infant delivered without signs of life after 20 weeks of gestation or weighing $>500$ grams when gestational age is not known. ${ }^{2}$ Intrauterine death can be due to various causes. ${ }^{3}$ It may be fetal causes, maternal causes or placental causes. Fetal causes include congenital malformations; infections due to TORCH, congenital syphilis, parvovirus B-19, rubella, varicella or listeriosis; immune or non-immune hydrops. Placental causes can be placental abruption, placenta previa, cord accidents, chorioamnionitis or twin-twin transfusion syndrome.

Maternal causes include hypertensive disorder of pregnancy, diabetes mellitus, hyperpyrexia due to any cause, trauma, sepsis, acidosis, shock, maternal medical conditions or labour related complications like abnormal labour, mismanaged labour, or uterine rupture. Stillbirth 
is a useful index to measure the values of antenatal and intra-natal care. Stillbirth is an event which has always challenged obstetrician. By proper antenatal check-ups, the high-risk cases associated with poor outcomes can be identified. In the last 4-5 decades, antenatal care has changed to great extent. Institutional delivery rate has increased in India.

So, intra-natal fetal surveillance and timely management for prevention of intra-partum death has improved in recent time. By strengthening of referral system, highrisk cases are referred to higher centres where proper management of high-risk mothers is possible. These have led to decrease in incidence of intrauterine death

Aim of our study was to determine incidence rate of intrauterine fetal death at tertiary care hospital to evaluate the maternal and fetal factors responsible for intrauterine fetal death and to find preventable causes of fetal death.

\section{METHODS}

This was a prospective study conducted at Rukmani Chainani Prasutigruh, SSG Hospital Vadodara, during period of 1 year, January 2019 to December 2019.

\section{Inclusion criteria}

All pregnant women coming to labour room with intrauterine Fetal death with singleton pregnancy with gestation age more than 28 weeks were included in study.

\section{Exclusion criteria}

28 weeks or less gestations, Baby weighing less than 1000 grams, multiple gestations were excluded from the study.

Present study was a prospective study of 462 cases of intrauterine fetal death admitted to our hospital during 1year study period from January 2019 to December 2019. Patients included in this study were from various socioeconomic classes and they were having different education level, different rural and urban locations and had different level of accesses to health care facilities. The details of complaints at admission, obstetrics history, examination findings, per vaginal examination findings, mode of delivery and fetal outcomes, placental examination, condition of cord and investigation reports were recorded.

The complaints included a period of amenorrhea, duration of labor pains, history of leaking, bleeding per vagina, pregnancy induced hypertension or eclampsia, decreased or loss of fetal movements, or associated medical conditions. Routine investigations including complete blood count, renal and liver function tests, blood grouping including Rh status and ultrasonography finding like placental location, cord abnormalities, spalding sign, Robert's sign, ball sign, crowding of ribs shadow, etc were noted. The details of the mode of delivery included vaginal delivery, lower segment caesarean section, and laparotomy for rupture uterus. Fetal outcomes included fresh/macerated stillbirth, sex of the baby, weight, congenital malformations, and birth injuries. Findings of placenta like infarction, calcification, and retroperitoneal clot and conditions of the cord like knots, cord around neck, and any other abnormality were also recorded.

\section{Statistical analysis}

This study was designed to record socio-demographic profile, complaint at admission, obstetric history, perabdominal and per-vaginal examination findings, mode of delivery, birth weight of fetuses, cause of intrauterine fetal death and congenital malformations if present. The data was analysed and presented in simple descriptive statistics using tables after collection. The results were presented as numbers and percentages. The analysed data was compared with different studies and discussed.

\section{RESULTS}

During the study period of one year, January 2019 to December 2019, a study conducted at our tertiary care hospital Rukmani Chainani Prasutigruh, a total of 462 intrauterine fetal deaths were reported amongst 7295 deliveries conducted during the study period.

Table 1: Sociodemographic profile and history.

\begin{tabular}{|lll|}
\hline Cases & Number & Percentage \\
\hline Booked cases & 121 & 26.19 \\
\hline Unbooked cases & 341 & 73.8 \\
\hline Residence & & \\
\hline Rural area & 268 & 58 \\
\hline Urban area & 194 & 42 \\
\hline Age distribution & & \\
\hline$<20$ years & 70 & 15.15 \\
\hline 20-30 years & 295 & 63.8 \\
\hline 30-40 years & 88 & 19.0 \\
\hline$>40$ years & 9 & 1.9 \\
\hline Maturity status of baby & & \\
\hline Premature & 217 & 47 \\
\hline Mature & 245 & 53 \\
\hline Type of still-birth & & \\
\hline Fresh still-birth & 312 & 67.5 \\
\hline Macerated still-birth & 150 & 32.5 \\
\hline Socio-economic profile & & \\
\hline Low-income group & 374 & 80.1 \\
\hline Middle income group & 55 & 11.9 \\
\hline High-income group & 33 & 8 \\
\hline Parity & & \\
\hline Primipara & 180 & 38.9 \\
\hline Second para & 98 & 21.2 \\
\hline Multipara & 184 \\
\hline
\end{tabular}


The incidence rate of intrauterine fetal death was 63/1000 live births. Out of 462 intrauterine death cases, 217 $(47 \%)$ were premature and $245(52 \%)$ were mature. 312 $(67.5 \%)$ were fresh stillbirths and 150 (32.5\%) were macerated.

It was noticed that $268(58 \%)$ cases were from rural areas and $194(42 \%)$ were from urban areas. $374(80.1 \%)$ cases were from low-income group, and 180 (38.9\%) cases were primipara.

Table 2: Causes of intrauterine fetal death.

\begin{tabular}{|lll|}
\hline Cause & Number & Percentage \\
\hline $\begin{array}{l}\text { Pregnancy induced } \\
\text { hypertension }\end{array}$ & 95 & 20.50 \\
\hline Antepartum haemorrhage & 55 & 12 \\
\hline $\begin{array}{l}\text { Trauma and stress of } \\
\text { labour }\end{array}$ & 74 & 16 \\
\hline $\begin{array}{l}\text { Maternal medical } \\
\text { condition }\end{array}$ & 58 & 12.50 \\
\hline Fetal growth retardation & 24 & 5.20 \\
\hline Congenital malformation & 37 & 8 \\
\hline Prematurity & 13 & 2.80 \\
\hline Unknown etiology & 106 & 23 \\
\hline
\end{tabular}

In our study, most common causes of intrauterine death were found to be pregnancy induced hypertension that accounts for $95(20.5 \%)$ cases. Second most common cause was stress related to labour that is $74(16 \%)$ cases.

Other causes were antepartum hemorrhage (12\%), maternal medical condition $(12.5 \%)$, congenital malformations $(8 \%)$, fetal growth retardation $(5.2 \%)$, prematurity $(2.8 \%)$. The cause of still-birth remains unknown in $106(23 \%)$ cases

Table 3: Congenital malformation present in delivered foetuses.

\begin{tabular}{|lll|}
\hline Type of malformation & $\begin{array}{l}\text { Number } \\
\text { of cases }\end{array}$ & $\begin{array}{l}\text { Percentage } \\
(\mathbf{n}=\mathbf{3 7})\end{array}$ \\
\hline Hydrocephalus & 15 & 3.6 \\
\hline Anencephaly & 12 & 2.8 \\
\hline Spina bifida & 4 & 0.86 \\
\hline $\begin{array}{l}\text { Multiple congenital } \\
\text { malformations }\end{array}$ & 4 & 0.86 \\
\hline Omphalocele major & 4 & 0.86 \\
\hline
\end{tabular}

A total of 37 cases of intra-uterine death cases were found to have congenital malformations. Most common congenital malformation was found to be hydrocephalus 15 cases $(3.6 \%)$ followed by anencephaly 12 cases $(2.8 \%)$.

Above Table shows that, $101(21.8 \%)$ cases delivered babies weighing 2.5 to $3 \mathrm{~kg}$, while maximum number of cases (114 (24.6\%) cases) delivered babies weighing 2 to $2.5 \mathrm{~kg}$.
Table 4: Distribution according to birth weight of stillborn foetuses.

\begin{tabular}{|lll|}
\hline $\begin{array}{l}\text { Birth } \\
\text { weight(grams) }\end{array}$ & $\begin{array}{l}\text { Number of still- } \\
\text { births }\end{array}$ & Percentage \\
\hline$<\mathbf{1 0 0 0}$ & 80 & 17.3 \\
\hline $\mathbf{1 0 0 0 - 1 5 0 0}$ & 87 & 18.8 \\
\hline $\mathbf{1 5 0 1 - 2 0 0 0}$ & 80 & 17.3 \\
\hline $\mathbf{2 0 0 1 - 2 5 0 0}$ & 114 & 24.6 \\
\hline $\mathbf{2 5 0 1 - 3 0 0 0}$ & 101 & 21.8 \\
\hline
\end{tabular}

Table 5: Distribution according to mode of delivery.

\begin{tabular}{|lll|}
\hline Mode of delivery & Number & Percentage \\
\hline Vaginal delivery & 410 & 88.8 \\
\hline LSCS & 50 & 10.8 \\
\hline $\begin{array}{l}\text { Laparotomy for } \\
\text { ruptured uterus }\end{array}$ & 2 & 0.4 \\
\hline
\end{tabular}

Out of 462 cases, $410(88.8 \%)$ are delivered vaginally, 22 $(5.36 \%)$ had prolonged labour, $50(10.8 \%)$ cases delivered by LSCS for obstructed labour or other reasons while 2 cases $(0.4 \%)$ had undergone laparotomy for ruptured uterus.

\section{DISCUSSION}

Although institutional delivery rate has improved with the government efforts, many deliveries occur at home and may result in still-births due to lack of supervision or some other reasons. So actual incidence of still-birth is not possible due to under-reporting of cases. For international comparisons, WHO considers stillbirths as pregnancy losses at or after 28 weeks of pregnancy, or a birth-weight of at least $1000 \mathrm{~g}$. worldwide, the stillbirth rate (SBR) has declined from $22 .{ }^{1}$

Stillbirths per 1000 births in 1995 to 18.9 stillbirths per 1000 births in $2009 .{ }^{3}$ Incidence of still-birth in our study is very much higher that is 63/1000 live births compared to Gehlot et al of 37.45/1000 live births and Patel et al of 22.2/1000 births., ${ }^{4,5}$ Incidence rate reported from particular center also depends on the area from where patients come and the referrals received from peripheral centers. As our SSG hospital is catering large area including middle Gujarat and Madhya Pradesh.

Majority of the IUFD cases are contributed from rural areas and low socio-economic group with low literacy rate. In our study, $58 \%$ cases were from rural population and $73.8 \%$ population were illiterate compared to Gehlot et al $70.34 \%$ and $75.18 \%$ of cases from rural area and illiterate respectively. ${ }^{4}$

This is due to low level of low attendance at antenatal clinics and paucity of antenatal care clinics and screening for high risk pregnancies. These unsupervised pregnancies lead to high rates of IUFD in rural and illiterate populations. Of $462,47 \%$ were premature and 
$53 \%$ were mature compared to Sharma et al. ${ }^{6}$ In our study, about $80.1 \%$ were from low-income group, $11.9 \%$ were from middle-income group and $8 \%$ from highincome group compared to Sharma et al in which similar results were obtained. ${ }^{6}$

In our study, $73.8 \%$ cases were unbooked emergency admissions while only $26.2 \%$ cases were booked cases compared to Korde et al. and Anjali et al. reported a higher still-birth rates in emergency admissions as $84.9 \%$ and $89.5 \%$ respectively. ${ }^{7,8}$ Kameshwaran et al. observed five times higher stillbirth rate in emergency cases. ${ }^{9}$

In our study, $38.9 \%$ of IUFD were primipara which is comparable to $38.6 \%$ of Gehlot et al. ${ }^{4}$ Higher numbers of IUFD seen in younger age group and teenagers in Indian population. In our study, highest numbers of IUFD $(63.8 \%)$ were seen in age group of 20-30 years which is comparable to Gehlot et al $(70.5 \%)$ and Patel et al $(81.2 \%) .^{4,5}$ This is due to early marriage and early age of childbearing in Indian population.

The incidence of antepartum hemorrhage contributing to IUFD in our study is $12 \%$ compared to Sharma et al $(12 \%) .{ }^{4}$ Incidence of IUGR $5.2 \%$ which is similar to Sharma et al and Gehlot et al.,6 Congenital anomalies were seen in $8 \%$ of cases compared to $11.3 \%$ cases of Gehlot et al. ${ }^{4}$

In our studies, $88.8 \%$ cases delivered per-vaginally and $11.2 \%$ patients had operative delivery which is compared to Patel S. et al of $91.2 \%$ of vaginal deliveries and $8.7 \%$ of operative deliveries. ${ }^{5}$ In our study only $0.4 \%$ cases had undergone laparotomy for ruptured uterus which is much lower compared to $7.2 \%$ of Sharma et al. ${ }^{6}$

\section{Limitations}

Actual incidence rate could not be found out with this study due to under-reporting of cases and some deliveries still take place at home. Incidence rate is higher because this hospital serves as referral center for large population near Baroda.

\section{CONCLUSION}

All antenatal women should be encouraged for regular antenatal check-up and ultrasound should be made available to find out congenital malformations at earliest. High risk pregnancy cases should be identified during routine antenatal check-ups so that intrauterine fetal death can be prevented. The mode of antepartum and intrapartum surveillance for fetal wellbeing should be advanced to prevent fetal demise.

\section{ACKNOWLEDGMENTS}

Authors would like to thank entire team of obstetricians of SSG Hospital, operation theatre and ICU staff, patients who participated in the study for their help and cooperation.

\section{Funding: No funding sources \\ Conflict of interest: None declared}

Ethical approval: The study was approved by the Institutional Ethics Committee

\section{REFERENCES}

1. Stanton C, LawnJ E, Rahman H, WilczynskaKetende K, Hill K. Stillbirthrates: delivering estimates in 190 countries. Lancet. 2006;367:1487-94.

2. WHO Stillbirths, 2014. Available at www.who.int/maternal_child_adolescent/epidemiolo gy/stillbirth/en/. Accessed on 16 August 2014.

3. Causes of fetal death, Williams obstetrics 25th edition. 2005:645.

4. Gehlot H, Nagar GG, Sharma S, Yadav OP. A prospective analytical study of intrauterine fetal death cases and associated maternal condition at a tertiary centre. Int $\mathbf{J}$ Reprod Contracept Obstet Gynecol. 2017;6(8):3392-6.

5. Patel S, Thaker R, Shah P, Majumder S. Study of causes and complications of intra uterine fetal death (IUFD). Int J Reprod Contracept Obstet Gynecol. 2014;3:931-5.

6. Sharma S, Sidhu H, Kaur S. Analytical study of intrauterine fetal death cases and associated maternal conditions. Int J Appl Basic Med Res. 2016;6(1):113.

7. Korde NV, Gaikwad P. Causes of stillbirth. J Obstet Gynaecol India. 2008;58(4):314-7.

8. Anjali C, Vineeta G. Epidemiology of Intrauterine fetal deaths: a study in tertiary referral center in Uttarakhand. IOSR J Dent Med Sci. 2014;13(3):036.

9. Kameshwaran C, Bhatia BD, Bhat BV, Oumachigui A. Perinatal mortality: a hospital based study. Indian Paediatr. 1993;30:997-1001.

Cite this article as: Tai NN, Mulchandani R, Modi DA, Rami B. A prospective study of intrauterine death cases at a tertiary care hospital. Int J Reprod Contracept Obstet Gynecol 2021;10:638-41. 